\title{
QUALITY OF LIFE OF PEOPLE LIVING WITH HIVIAIDS IN KOGI STATE, NIGERIA
}

\author{
${ }^{*}$ A. A. Fatiregun, ${ }^{*}$ K. C. Mofolorunsho, ${ }^{* *}$ K. G. Osagbemi \\ *Department Of Epidemiology, Medical Statistics and Environmental Health, Faculty \\ of Public Health, College of Medicine, University of Ibadan, Ibadan, Nigeria \\ ${ }^{* *}$ College of Health Sciences, University of Ilorin, Ilorin Nigeria
}

\section{Correspondence:}

Dr A. A. Fatiregun

Department of Epidemiology, Medical Statistics and Environmental Health

Faculty of Public Health, College of Medicine

University of Ibadan

Ibadan, Nigeria

Email:akinfati@yahoo.com

\section{ABSTRACT}

Introduction: With the appreciable rise in longevity of people living with HIVIAIDS (PLWHA), the need for supporting their quality of life (QoL) has become increasingly important. However, limited studies have been conducted using the World Health Organization quality of life HIV (WHOQOL-HIV) bref in our environment.

Objective: This study assessed the QoL of PLWHA attending antiretroviral (ARV) clinics in Kogi State in north central Nigeria.

Methods: A descriptive crosssectional study design was used. Two hundred fifty-two PLWHA from five health care centres located across the three zones of Kogi State in Nigeria were consecutively selected. A questionnaire, administered at interview and containing data on sociodemographic, medical, and the WHOQOL-HIV bref was used to assess each study participant.

Results: The overall QoL mean scores in the three domains were similar: psychological health, 15.0 \pm 2.8 ; physical health, 15.2 \pm 2.5 ; and spirituality/religion/personal beliefs, 15.7 \pm 3.4. Lower QoL mean scores were observed in social relationships

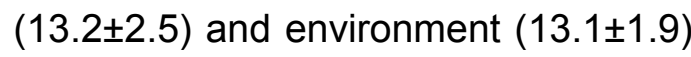
domains. A significant difference in mean QoL scores in the level of independence domain was observed among women $(14.4 \pm 1.9)$ compared to men $(13.9 \pm 1.7 ; p=0.028)$.

Conclusions: Lower QoL in the environment and social relationships domains may be suggestive of stigma and discrimination, as well as poor living conditions, in the PLWHA physical environment.

Key words: Quality of life, PLWHA, HIV, AIDS, WHOQOL-HIV bref.

\section{INTRODUCTION}

By the end of 2007, 33.2 million people worldwide were living with HIV; 2.5 million people became newly infected and 2.1 million people had lost their lives to AIDS in the same year ${ }^{1}$. With the alarming increase in the HIVIAIDS pandemic in developing countries, and the limited accessibility and availability of highly active antiretroviral therapy (HAART), the majority of people living with HIVIAIDS (PLWHA) continue to suffer with the disease, with a serious impact on their quality of life (QoL) $)^{2}$.

HIVIAIDS continues to contribute significantly to public health problems in Nigeria. Although HIV 
infection was initially limited to people with risky behaviors, such as commercial sex workers (CSWs), adolescents, youths, prisoners, and people with multiple sexual partners, the currently available evidence suggests that this infection has permeated all strata of the Nigerian population ${ }^{1}$. The prevalence of the infection is estimated to have accounted for about $20 \%$ of the total disease burden globally ${ }^{3-6}$. AIDS has a chronic debilitating course and as such, determining the impact on the QoL in PLWHA is important for estimating the burden of the disease ${ }^{7}$.

QoL is a term that is popularly used to convey an overall sense of well-being and includes aspects, such as happiness and satisfaction with life as a whole. QoL relates both to the adequacy of material circumstances and to personal feelings about these circumstances with overall subjective feelings of well-being that is closely related to morale, happiness, and satisfaction $^{8-10}$. QoL has recently been scientifically-defined and it has been considered synonymous with health status, functional status, psychological well-being, happiness with life, satisfaction of needs, and assessment of one's own life ${ }^{11}$.

Several instruments for measuring QoL have been developed and described ${ }^{12}$. The validity of the WHOQOL-HIV bref instrument used among HIVIAIDS patient has also been documented ${ }^{13}$. However, limited studies have been conducted using the WHOQOL-HIV bref in our environment $^{11}$. The current study assessed the QoL of PLWHA attending anti-retroviral therapy clinics in health care centres in Kogi State in north central Nigeria. Kogi State is one of the high-risk states in Nigeria for HIVIAIDS, with a prevalence of $5.5 \%$ in the general population ${ }^{14}$.

\section{METHODS}

This was a descriptive, crosssectional study. PLWHA (252) were consecutively recruited from the following five health care facilities in Kogi State: the Federal Medical Centre Lokoja (47), Partners Against AIDS in the Community (PAAC) Obangede (60), St. John's Catholic Hospital Kabba (56), Grimard Hospital Anyigba (53), and the Evangelical Church of West Africa (ECWA) Hospital Egbe (36). A questionnaire, administered at the time of interview and containing data on socio-demographic, medical, and the WHOQOL-HIV bref instrument was used to assess each study participant. The WHOQOL-HIV bref consists of 31 items, with each item using a 5-point Likert scale. These items are distributed in six domains. The six domains of QoL are as follows: physical health, psychological health, level of independence, social relationships, environment, and spirituality/religion/personal beliefs. The physical health domain measures pain and discomfort, energy and fatigue, and sleep and rest. The psychological health domain measures positive feelings, thinking, learning, memory and concentration, selfesteem, bodily image and appearance, and negative feelings. The level of the independence domain measures mobility, daily life activities, dependence on medications or treatments, and work capacity. The social relationships domain includes personal relationships, social support, and sexual activity. The environment domain measures physical safety and security, home environment, financial resources, health and social care, accessibility and quality, opportunities for acquiring new information and skills, participation in and opportunities for recreation and leisure activities, and physical environment (pollution, noise, traffic, climate, and transport). 
The spirituality/religion/personal beliefs domain measures forgiveness and blame, concerns about the future, and death and dying ${ }^{15}$.

Data entry and statistical analysis were performed using the statistical package for social science (SPSS) software, version 14.0. The descriptive statistics, such as mean and standard deviation, were used to summarize the score of the QoL. Domain scores were scaled in a positive direction (higher scores denoting a higher QoL). The mean score of items within each domain was used to calculate the domain scores by multiplying by 4 , so that scores ranged from 4 (minimum) to 20 (maximum), with higher scores indicating a better QoL. For the analysis of statistical differences between the mean scores of QoL for dichotomous variables, the student t-test was used. The level of statistical significance was set at $\mathrm{p}<0.05$.

\section{RESULTS}

Of the 252 PLWHA who participated in the study, $62.7 \%$ were females. The mean age of participants was 34.8 years, with a range of $18-58$ years. The majority of the participants were of Ebira (25.8\%) and Igala $(25.8 \%)$ ethnic groups, while Yoruba accounted for $23.8 \%$ of the participants. The married respondents constituted more than one-half of the entire sample size $(51.6 \%)$, while $23.8 \%$ were unmarried. Educational status showed that $67.5 \%$ of the respondents were educated up to the secondary school level (Table I).

Table I: SOCIO-DEMOGRAPHIC STATUS OF THE RESPONDENTS

$\begin{array}{llll}\text { Variables } & \text { Categories } & \text { N } & \text { \% } \\ \text { Gender }(\mathbf{n = 2 5 2 )} & \text { Male } & 94 & 37.3 \\ & \text { Female } & 158 & 62.7 \\ \text { Tribe (n=252) } & \text { Yoruba } & 60 & 23.8 \\ & \text { Ebira } & 65 & 25.8 \\ & \text { Igala } & 65 & 25.8 \\ & \text { Bassa } & 13 & 5.2 \\ & \text { others } & 49 & 19.4 \\ \text { Marital } \quad \text { status } & \text { Married } & 130 & 51.6 \\ \text { (n=252) } & \text { Single } & 60 & 23.8 \\ & \text { Widowed } & 26 & 10.3 \\ & \text { Divorced } & 16 & 6.3 \\ & \text { Separated } & 12 & 4.8 \\ & \text { Co-habitation } & 8 & 3.2 \\ \text { Educational } & \text { Primary } & 72 & 28.6 \\ \text { status (n=252) } & \text { Secondary } & 98 & 38.9 \\ & \text { Tertiary } & 38 & 15.1 \\ & \text { None } & 44 & 17.5\end{array}$

The mean scores in the domains of QoL were high for spirituality/religion/personal beliefs and the psychological domain, but lower for environment and social relationships. Table II shows a summary of the QoL domain scores. 
Table II: DISTRIBUTION OF MEANS, STANDARD DEVIATIONS, AND RANGE OF RAW SCORES OBTAINED FROM THE QUALITY OF LIFE QUESTIONNAIRE (WHOQOL-HIV bref) BY DOMAIN

\begin{tabular}{lcc}
\hline Domain & Mean (SD) & Minimum - Maximum \\
1. Physical health & $15.2(2.5)$ & $4.0-20.00$ \\
2. Psychological health & $15.0(2.8)$ & $4.0-20.00$ \\
3. Level of independence & $14.2(1.9)$ & $4.0-20.00$ \\
4. Social relationships & $13.2(2.5)$ & $4.0-20.00$ \\
5. Environment & $13.1(1.9)$ & $4.0-20.00$ \\
6.Spirituality/religion/personal & $15.7(3.4)$ & $4.0-20.00$ \\
beliefs & & \\
& &
\end{tabular}

The gender status of the PLWHA showed a significant difference in only the level of independence domain of the QoL. The results of the Student t-test between gender and domain scores are summarized in Table III.

Table III: GENDER AND QUALITY OF LIFE SCORES

\begin{tabular}{|lcc|c|}
\hline Domain & \multicolumn{1}{c}{ Male } & Female & p-value \\
& Mean (SD) & Mean (SD) & \\
\hline Physical health & $15.2(2.7)$ & $15.2(2.5)$ & 0.834 \\
\hline Psychological & $14.7(2.8)$ & $15.2(2.7)$ & 0.204 \\
\hline Level of independence & $13.9(1.7)$ & $14.4(1.9)$ & 0.028 \\
\hline $\begin{array}{l}\text { Social relationship } \\
\text { Environmental }\end{array}$ & $13.0(2.5)$ & $13.2(2.6)$ & 0.354 \\
\hline $\begin{array}{l}\text { Spiritual/religious/ } \\
\text { personal beliefs } \\
\text { Independent samples test }\end{array}$ & $13.0(1.9)$ & $13.2(1.9)$ & 0.383 \\
\hline
\end{tabular}

\section{DISCUSSION}

In this study, the mean score was highest and similar in the spirituality/religion/personal beliefs, physical, and psychological health domains, indicating a better QoL in these domains. However, the mean scores in the social relationships and environment domains were at the intermediate level. As documented by Ebisabete et al. $(2007)^{11}$ in a study conducted to assess the QoL of PLWHA in Sao Paulo, Brazil, the results showed that mean scores for social relationships and environment domains fell in the intermediate level, a result observed to be similar with the present study. Also, in a study conducted in Casa da by Fleck et al. (2000), PLWHA had a better QoL (i.e., physical and psychological health), but worse QoL in the social relationship 
domain ${ }^{16}$. The resulting low level QoL in the social relationships domain could reflect stigmatization and discrimination faced by the participants. Also, issues like personal relationships, sexual activities, and social support of PLWHA can have a negative effect in the social relationship domain.

In the current study, women showed a higher QoL score compared to men in virtually all domains and a significantly higher level on the independence domain. However, previous studies have reported lower QoL scores in psychological and environment domains among women $^{11,17,18}$. The reason for the observed higher QoL scores in women could be due to constant visits and show of concern among the females in our environment.

Generally, especially in a country like Nigeria, people tend to be spiritual and religious only when confronted with issues that are beyond them. This could account for the observed high QoL scores in the spirituality/religion/personal belief domain. A paper by Szaflarki et al. ${ }^{19}$ reported that one-third of patients with HIVIAIDS believed that their life was better now than before they were diagnosed with HIV. Several factors, including spirituality were associated with believing that life has improved. Szaflarki and his colleagues ${ }^{19}$ used path analysis to examine the conceptual model of how spirituality/religion is related to QoL. Ironson et al. $^{20}$ in their study to examine the relationship between changes in spirituality/religion post-HIV diagnosis and disease progression, observed that nearly one-half of the patients reported an increase in spirituality/religion following diagnosis and as such, their findings corroborated with those of Szaflarski and his colleagues ${ }^{19}$, confirming that


studied appear to have a higher QoL in the spirituality/religion/personal beliefs, physical, and psychological health domains, but a lower QoL in the social relationships and environment domains, which could be an indication of discrimination as well as poor living conditions in their physical environment.

\section{REFERENCES}

1. UNAIDS. AIDS epidemic update. World Health Organization, Geneva. UNAIDS/ 07.27E/JC1322E, 2007.

2. O'Connell $\mathrm{K}$, Skevington $\mathrm{S}$, Saxena S. WHOQOL HIV Group. Preliminary development of the World Health Organization's quality of life HIV instrument (WHOQOLHIV): Analysis of the pilot version. Soc Sci Med 2003; 57: 1259-75.

3. WHO. The World Health Report 2004, Changing History. Geneva: World Health Organization, 2004.

4. Arowojolu $\mathrm{AO}$, llesanmi $\mathrm{AO}$, Roberts OA, Okunlola MA. Sexuality, contraceptive choice and AIDS awareness among Nigerian undergraduates. Afr $\mathrm{J}$ Repro. Health 2002; 6(2): 6070.

5. Ajuwon AJ, Mcfarland W, Hudes E, Adedapo S, Okikiolu $T$, Lurie $P$. Risk related behavior, sexual coercion and implications for prevention strategies among female 
apprentice tailors, Ibadan Nigeria. Aids and Behaviors 2002; 6(3): 233-234.

6. World AIDS Day 2006 in Nigeria. Available at www.worldbank.org. Accessed July 162008.

7. Wig $N$, Lekshmi $R$, Pal $H$, Ahuja $V$, Mittal CM, Agarwal SK. The impact of HIVIAIDS on the quality of life: A cross sectional study in North India. Indian J Med Sci 2006; 60: 3-12.

8. Lesserman J, Perkins DO, Evans DL. Coping with the threat of AIDS: The role of social support. Am J Psychiatr 1992; 149:1514-20.

9. Namir S, Wolcott D, Fawzy F, Alumbaugh M. Implications of different strategies for coping with AIDS. In: L. TEMOSHACK and A.BAUM (Editors) Psychological perspectives on AIDS, Hillsdales NJ: Erlbaum Associates; 1990; 173-90.

10. Rabkin JG, Remien R, Kattoff L, Williams JB. Residence in adversity among long time survivors of AIDS. Hosp Comm Psychiatr 1993; 44:162-7.

11. Elisabete C, Morandi Dos Santos, Ivan FJ, Fernanda L. Quality of life of people living with HIVIAIDS in São Paulo, Brazil. Rev Saúde Pública 2007; 741(Suppl. 2) : 647

12. McDowell I, Newell C. Measuring health: $A$ guide to rating scales and questionnaires. ( $2^{\text {nd }}$ ed.) New York: Oxford U Pr. 1996.
13. Saxena S, O'Connell K, Underwood L. A commentary: Cross-cultural quality-of-life assessment at the end of life. The Gerontologist 2002; 42 special issue iii: 81-85.

14. FMOH.Technical Report 2005 National HIVIAIDS and Reproductive Health Survey, 2005.

15. Fleck MPA, Fachel O, Louzada S, Xavier M, Chachamovich E, Vieira G, et al. Desenvolvimento da versão em português do instrumento de avaliação de qualidade de vida da Organização Mundial da Saúde (WHOQOL-100). Rev ABPAPAL. 1999; 21:19-28.

16. Fleck MPA, Louzada S, Xavier $M$, Chachamovich E, Vieira G, Santos $L$ et al. Aplicação da versão em português do instrumento abreviado de avaliação da qualidade de vida "WHOQOL-bref". Rev Saude Publica 2000; 34(2):178-83.

17. Mrus JM, Williams PL, Chon ST, Wu AW, Tseva J. Gender differences in health-related quality of life in patients with HIVIAIDS. Quality of Life Research: An International Journal of Quality of Life Aspects of Treatment, Care and Rehabilitation 2005; 14(2): 479491.

18. Wisniewski AB, Apel S, Selnes OA, Nath A, McArthur JC, Dobs AS. Depressive symptom, quality of life and neuropsychological performance in HIVIAIDS: the impact of gender and injection drug use. J Neurovirol 2005; 11(2):138-43. 
19. Szaflarski M, Ritchey PN, Leonard AC, Modeling the effects of spirituality/religion on patients' perceptions of living with HIVIAIDS. J Gen Intern Med 2006; 21:S28-38.
20. Ironson, G, Stuetzle R, Fietcher MA. An increase in religiousness/spirituality occurs after HIV diagnosis and predicts slower disease progression over 4 years in people living with HIV. J Gen. Intern Med 2006; 21:S62-68. 